\title{
Spektrofotometer Quali-Vis dan Kemometrika untuk Klasifikasi Kualitas Daun Wungu (Graptophyllum pictum)
}

\author{
Penulis \\ Silvi Agusri Putri ${ }^{1}$, Rudi Heryanto ${ }^{1,2}$, Eti Rohaeti ${ }^{1 *}$ \\ Afiliasi \\ ${ }^{1}$ Departemen Kimia, Fakultas Matematika dan IImu Pengetahuan Alam, Institut Pertanian Bogor, \\ Indonesia \\ ${ }^{2}$ Pusat Studi Biofarmaka Tropika, Institut Pertanian Bogor, Indonesia
}

\section{Kata Kunci \\ ○ Daun wungu \\ (Graptophyllum pictum) \\ $\rightarrow$ PCA \\ $\rightarrow$ PLS-DA \\ - Quali-vis \\ $\rightarrow$ Sidikjari KLT}

Diterima 25 Juli 2018

Direvisi 1 September 2018

Disetujui 3 Oktober 2018

* Penulis Koresponding Eti Rohaeti

Jl. Tanjung Kampus IPB, Dramaga, Babakan, Dramaga, Bogor, Jawa Barat 16680 Email: er_a444@hotmail.com

\section{ABSTRAK}

Spektrofotometer Quali-Vis digunakan untuk mengklasifikasikan 3 sampel daun wungu dengan usia panen berbeda. Penelitian ini bertujuan mengevaluasi model klasifikasi menggunakan spektrofotometer Quali-Vis secara kualitatif. Model dikembangkan dengan akuisisi data menggunakan principle component analysis (PCA) dan partial least square-discriminant analysis (PLS-DA). Karakteristik awal sampel daun wungu ditentukan dengan analisis sidik jari kromatografi lapis tipis (KLT) yang menampilkan profil yang berbeda pada masing-masing usia panen. Perbedaan ini menjadi dasar klasifikasi untuk model PLS-DA yang terdiri atas model usia 1 bulan, 2 bulan, dan 3 bulan, yang menghasilkan rerata $R_{\text {pred }}^{2} 0.7794$ dan root mean square error predict $($ RMSEP $)=0.2180$. Model divalidasi dengan menentukan nilai parameter sensitivitas, spesifitas, presisi, dan akurasi yang menghasilkan nilai rerata masingmasing $0.95,0.99,0.98$, dan 0.98 kesesuaian prediksi. Nilai-nilai ini menunjukkan bahwa model yang dikembangkan memiliki kemampuan klasifikasi yang cukup baik.

\section{PENDAHULUAN}

Tanaman obat menjadi semakin populer di kalangan masyarakat karena penggunaan obat dari tanaman dianggap relatif lebih aman dibandingkan obat sintetis. Kualitas obat herbal ini ditentukan oleh komposisi senyawa kimia aktif yang terkandung didalamnya. Adapun komposisi senyawa kimia yang beragam pada suatu tanaman dipengaruhi kondisi geografis, budidaya, metode pemanenan, dan proses pasca panen (Singh et al. 2010). Faktor lain yang dapat memengaruhi komposisi senyawa kimia adalah perbedaan umur dari tanaman obat tersebut (Anuradha 2010). Perbedaan ini menyebabkan diperlukannya kendali mutu untuk mengontrol kualitas dari tanaman obat.

Kendali mutu dapat dilakukan dengan teknik kromatografi maupun spektrofotometri (Singh et al. 2010). Spektrofotometri sinar tampak merupakan teknik, yang umum digunakan pada berbagai analisis komponen kimia pada rentang variasi 
matriks yang cukup luas. Teknik ini memiliki cara pengukuran tipe absorbans, transmitans, dan reflektans dalam analisisnya. Tipe absorbans paling sering digunakan, namun pengukuran absorbans hanya terbatas pada sampel campuran homogen atau larutan. Oleh sebab itu, dibutuhkan alternatif lain pada anlisis sampel campuran heterogen berupa padatan, misalnya pengukuran reflektans. Reflektans adalah jumlah fluks yang dipantulkan suatu permukaan sebagai fungsi dari panjang gelombang. Basis reflektans memiliki kelebihan dapat diaplikasikan pada sampel campuran heterogen (pada wujud padatan atau serbuk), waktu analisis cepat, dan dapat diterapkan untuk jumlah sampel yang besar (Andor 2014). Sistem reflektans dipilih karena dalam penggunaannya, spektrofotometer dapat digunakan untuk padatan secara langsung tanpa preparasi.

Spektrofotometer reflektans sinar tampak yang digunakan pada penelitian ini merupakan alat yang sudah dirancang secara mandiri dengan komponen elektronik berdasarkan Public Laboratory (2014) dan memiliki desain komponen sesuai dengan Rahma (2016) yang disebut Quali-Vis. Komponen-komponen dari alat ini terdiri dari lampu LED senter Police Swatt 1300 lumen, kompartemen sampel yang dilengkapi kaca preparat sebagai medium pemantul, pemilih panjang gelombang berupa monokromator kisi yang dibuat dari lapisan optik DVD berukuran $2 \times 2 \mathrm{~cm}^{2}$, serta detektor berupa web kamera yang dilengkapi sensor charge couple device (CCD) sebagai detektor yang dihubungkan dengan peranti lunak berbasis web Spectral Workbench (Lampiran 3). Spektrofometer Quali-vis digunakan dalam penelitian ini untuk kendali mutu tanaman obat yaitu daun wungu.

Tanaman wungu (Graptophyllum pictum (L.) Griff) merupakan tanaman obat yang sering dimanfaatkan masyarakat sebagai tanaman hias di pekarangan rumah karena warnanya yang unik. Tanaman ini memiliki khasiat untuk mengatasi penyakit wasir dan sembelit, melancarkan buang air seni, dan melancarkan haid (Aminah et al 2016). Jiangseubchatveera et al. (2017) melaporkan adanya kandungan flavonoid, steroid, tanin, saponin dan fenolik dalam daun wungu yang membuat daun wungu berpotensi menjadi antioksidan. Penelitian ini melakukan kendali mutu daun wungu berdasarkan usia panennya. Usia panen yang dipilih adalah usia 1 bulan, 2 bulan dan 3 bulan. Studi mengenai pengaruh usia panen terhadap senyawa metabolit daun wungu belum dilakukan. Namun, penelitian lain mengenai pengaruh usia panen daun tanaman herbal terhadap kandungan senyawa metabolitnya sudah dilakukan, seperti yang dilaporkan Blum-Silva et al. (2015), bahwa adanya variasi kandungan senyawa metilxantin dan total fenolik dalam daun teh yerba mate (Ilex paraguariensis) pada umur 1 bulan, 2 bulan dan 6 bulan. Karakterisasi awal dilakukan dengan menggunakan teknik kromatografi lapis tipis. Pola sidik jari yang dihasilkan menunjukkan perbedaan luas puncak pita untuk senyawa yang sama pada masing-masing bulan. Selanjutnya klasifikasi menggunakan spektrofotometer Quali-Vis dilakukan dengan memanfaatkan karakteristik optik dari ketiga sampel uji.

\section{METODE}

Penelitian ini terdiri dari 5 tahapan: (i) persiapan sampel dimulai dari pemangkasan, penumbuhan daun, pemanenan, pencucian, penyerbukan, serta pengeringan sampel menggunakan oven hingga kadar airnya konstan, (ii) pembuatan pola sidikjari dengan kromatografi lapis tipis dan pengolahan pola dengan piranti lunak image J, (iii) kalibrasi spektrofotometer reflektans Quali-Vis dengan $\mathrm{BaSO}_{4}$, (iv) desain sampel dan pengukuran reflektans sampel menggunakan spektrofotometer Quali-Vis, serta (v) analisis multivariat PCA dan PLS-DA menggunakan piranti lunak The Unscrambler X 10.4 (Lampiran 1).

\section{Persiapan Sampel}

Sampel diambil dari kebun percobaan Pusat Studi Biofarmaka Tropika LPPM IPB Cikabayan. Sebanyak 21 batang tanaman wungu yang tersedia dipangkas bersih tidak meninggalkan 1 daun tersisa, lalu diamati pertumbuhannya secara berkala tiap 3 hari, dan ditandai tanggal daun tumbuh. Perlakuan tambahan dilakukan seperti mengatasi hama atau ulat secara manual dan pemberian pupuk organik. Lalu pada saat pemanenan diambil daun yang berumur satu bulan (30 hari) sebanyak lebih kurang $1 \mathrm{~kg}$ dan disisakan untuk 2 bulan berikutnya. Sampel bulan ke-1 dikeringkan menggunakan oven dengan suhu $60^{\circ} \mathrm{C}$. Setelah kering, sampel selanjutnya dihaluskan menjadi serbuk berukuran 60 mesh dan disimpan.

\section{Penentuan Kadar Air}

Metode penentuan kadar air mengacu pada AOAC 935.29 2012. Cawan porselin kosong dikeringkan dalam oven bersuhu $103-105{ }^{\circ} \mathrm{C}$ selama 30 menit, kemudian

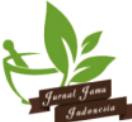


didinginkan dalam desikator selama 30 menit dan ditimbang bobot kosongnya. Sebanyak 5 gram sampel ditimbang ke dalam cawan yang telah diketahui bobotnya. Cawan berisi sampel dikeringkan dalam oven bersuhu $103-105{ }^{\circ} \mathrm{C}$ selama 3 jam. Cawan didinginkan dalam desikator selama 30 menit dan ditimbang bobotnya. Proses pengeringan dalam oven dilakukan hingga bobot konstan. Penentuan kadar air dilakukan 3 kali ulangan.

$$
\text { Kadar air }(\%)=\frac{A-B}{A} \times 100 \%
$$

Keterangan :

$A=$ bobot sampel sebelum pengeringan ( $\mathrm{g}$ )

$B=$ bobot sampel setelah pengeringan (g)

\section{Pembuatan Pola Sidikjari dengan Kromatografi Lapis Tipis}

Pola sidikjari kromatografi lapis tipis dibuat dengan mengacu pada Farmakope Herbal Indonesia (Depkes RI 2010). Sebanyak 1 gram serbuk daun wungu ditimbang dan diekstraksi secara sonikasi dengan $10 \mathrm{~mL}$ metanol p.a selama 40 menit. Hasil sonikasi disaring dan filtratnya dipindahkan ke wadah lain. Ekstrak setiap sampel daun wungu dalam metanol ditotolkan pada pelat silika gel $\mathrm{F}_{254}$ menggunakan syringe $15 \mu \mathrm{L}$ dibantu dengan KLT sampler semiautomatik CAMAG Linomat 5 dengan lebar pita tiap sampel adalah $8 \mathrm{~mm}$. Pelat yang akan digunakan dielusi terlebih dahulu dengan methanol p.a kemudian dikeringkan. Eluen yang digunakan adalah etil asetat-asam format-asam asetat glasial-air (10:1.1:1.1:2). Eluen tersebut dijenuhkan selama 30 menit di dalam bejana kromatografi. Pelat yang telah diaplikasikan sampel dimasukkan ke dalam bejana kromatografi untuk proses elusi. Deteksi pola sidikjari dilakukan dengan CAMAG TLC scanner Reprostar 3 dengan sinar UV $254 \mathrm{~nm}$ dan $366 \mathrm{~nm}$. Pola sidikjari yang diamati pada sinar uv $366 \mathrm{~nm}$ diolah menggunakan peranti lunak Image J.

\section{Pengolahan Pola Sidikjari Kromatogram Daun Wungu menggunakan Piranti Lunak Image J}

Perangkat lunak Image J dibuka lalu dipilih menu File-Open. Lalu dipilih gambar KLT yang telah didokumentasi dengan CAMAG Reprostar 3 dengan format .jpg. Menu Rectangular diaktifkan lalu diblok pada gambar target yang akan dianalisis, dipilih menu Analyze-Gels-Select First Lane. Gambar diatur kontrasnya dengan cara memilih menu Image-typedan dipilih RGB colour, lalu dipilih menu Adjust dan diatur Brightness dan Contrast sesuai kebutuhan sampai didapat gambar titik yang jelas. Kemudian dipilih kembali menu Analyze-Gels-plot line, maka akan muncul kurva densitogram yang sesuai dengan gambar KLT. Kurva densitogram ini akan menunjukkan jumlah pita yang terdapat pada pelat KLT. Kurva tersebut kemudian diubah menjadi Line Graph dengan cara menu Rectangular diaktifkan lalu bagian kurva diblok, kemudian dipilih menu Analyze-Tools-Analyze line graph sehingga akan muncul tampilan kurva dalambentuk kurva Xycoordinat. Lalu dipilih menu Copy untuk mengubah gambar menjadi informasi dalam bentuk angka. Kemudian Paste pada piranti lunak MS.Excel untuk pengolahan kurva selanjutnya.

Menentukan luas puncak densitogram, dibuka kurva densitogram kemudian dipilih salah satu puncak kurva dan dipilih menu Straight diaktifkan lalu ditarik bagian dasar puncak ujung satu ke ujung lainnya (jika terdapat beberapa puncak kurva buat garis dasar pada masingmasing puncak kurva), kemudian menu Wand diaktifkan. Masing-masing daerah puncak kurva diberi Highlight dengan mengarahkan kursor pada daerah kurva yang dipilih tersebut kemudian akan muncul Report berupa luas puncak.

\section{Kalibrasi Spektrofotometer Reflektans}

Spektrofotometer Quali-Vis dikalibrasi menggunakan lampu neon. Pengukuran dilakukan terhadap BaSO4 sebagai matrik. BaSO4 dibentuk menjadi lapisan film tipis yang melekat pada kaca preparat kemudian diletakkan pada kompartemen sampel dan diukur. Hasil pengukuran berupa spektrum cahaya dan spektrum intensitas RGB. Spektrum disimpan dengan memilih menu Save. Kemudian dibuatkan suatu identitas pada spektrum dan dipilih menu Save \& Calibrate later. Setelah itu, spektrum yang memiliki intensitas tertinggi dipilih pada warna biru dan hijau, dan dipilih menu Save kemudian menu Calibrate. Kalibrasi dilakukan untuk mendapatkan skala panjang gelombang yang tepat sehingga dapat dijadikan sebagai acuan panjang gelombang pada saat pengukuran.

\section{Pengukuran Reflektans Sampel}

Pengukuran reflektans sampel mengacu pada yang dilakukan Hafsah (2017), sampel dibagi menjadi A mewakili usia 1 bulan, B untuk usia 2 bulan, dan C untuk usia 3 bulan. Sampel masing-masing dibagi 
menjadi dua bagian, yaitu training set dan testing set. Training set merupakan set sampel yang akan diukur reflektansnya untuk menghasilkan model klasifikasi, sedangkan testing set merupakan set sampel yang akan menguji kemampuan klasifikasi model yang telah dihasilkan (Gambar 1).

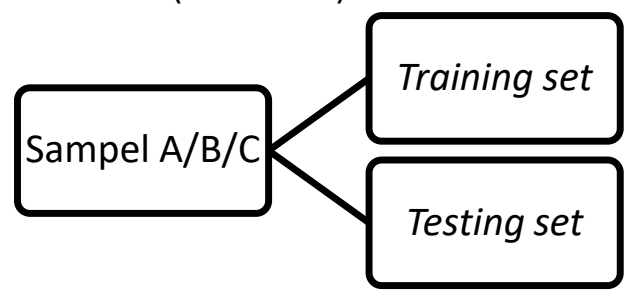

Gambar 1 Penampang bagian sampel

Tabel 1 Desain sampel daun wungu

\begin{tabular}{ccc}
\hline Sampel & Training set & Testing set \\
\hline A & 60 & 20 \\
B & 60 & 20 \\
C & 60 & 20 \\
\hline
\end{tabular}

Sebanyak 60 sampel dan 20 sampel diperoleh dengan teknik random picking menggunakan tabel bilangan acak (Tabel 1). Teknik random picking tersebut dilakukan dengan meratakan masing-masing sampel A, $B$ dan $C$ pada permukaan datar dan memisahkan sampel menjadi 100 bagian dengan bobot $300 \mathrm{mg}$ yang kemudian dinamai setiap bagiannya. Kemudian, dipilih 60 sampel dari Ms Excel sebagai sampel representatif untuk menghasilkan model klasifikasi. Setelah set sampel diperoleh, sampel daun wungu yang merupakan padatan berbentuk serbuk dicetak menjadi pelet dengan pencetak pelet. Pelet diletakkan pada kompartemen sampel Quali-Vis. Sinar polikromatik yang berasal dari sumber sinar senter LED dikirim menuju sampel melewati celah dan kompartemen sampel yang sekaligus berperan sebagai medium pemantul (kaca preparat). Saat mengenai pelet, sinar mengalami serapan dan pantulan bergantung pada warna dan banyaknya kandungan matriks yang mampu menyerap sinar tampak pada sampel. Detektor akan menangkap intensitas pantulan pada kisaran panjang gelombang tertentu dengan pemilih panjang gelombang berupa monokromator kisi. Data yang diperoleh berupa data spektrum cahaya yang diubah menjadi data intensitas RGB terhadap panjang gelombang dalam format .csv. Nilai rerata intensitas RGB dikonversi menjadi nilai reflektans menggunakan persamaan persen intensitas (persamaan 1) dan reflektans (persamaan 2) sehingga diperoleh nilai reflektans sampel. Selanjutnya, pengolahan data dilanjutkan dengan pengenalan pola data spektrum menggunakan piranti lunak The Unscrambler $X 10.1$.

$$
\begin{aligned}
& \left.\% I=\frac{I}{257} \times 100 \% \text { (persamaan } 1\right) \\
& \left.R=\log \frac{\% \text { I blanko }}{\% \text { I sampel }} \text { (persamaan } 2\right)
\end{aligned}
$$

Keterangan :

$\% \mathrm{I}=$ persen instensitas

$\mathrm{R}=$ reflektans

$\mathrm{I}_{\text {blanko }}=$ persen intensitas blanko

$\mathrm{I}_{\text {sampel }}=$ persen intensitas sampel

\section{Analisis Multivariat}

Nilai reflektans yang diperoleh dari hasil pengukuran selanjutnya dianalisis menggunakan analisis multivariat berupa PCA dan PLS-DA. Berikut merupakan tabulasi data multivariat yang akan dianalisis pada penelitian ini.

\section{Principle Component Analysis (PCA).}

Proses pengolahan data reflektans sampel A, B dan C dilakukan dengan penentuan pola distribusi kelompok sampel menggunakan PCA dengan memanfaatkan data reflektans pada rentang panjang gelombang 450-600 $\mathrm{nm}$. Hasil analisis menggunakan PCA diharapkan mampu memisahkan sel data ke dalam 3 kelas yaitu sampel A, B, dan C.

Partial Least Square-Discriminant Analysis (PLS-DA).

Akuisisi data selanjutnya adalah pembuatan model klasifikasi dan uji diskriminan menggunakan metode PLS-DA dengan peranti lunak The Unscrambler $X$ 10.1. Model PLS-DA dibuat menggunakan matriks data reflektans hasil analisis spektrofotometer (matriks $\mathrm{x}$ ) dan data rujukan dummy variable (matriks y). Model terdiri dari $\operatorname{ModA}(1,0,0)$, $\operatorname{ModB}(0,1,0)$, dan $\operatorname{ModC}$ $(0,0,1)$ dengan Kebaikan model prediksi diukur dengan nilai $R^{2}$ mendekati 1 dan root mean square error (RMSE) mendekati 0 .

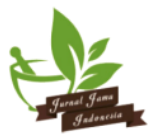


Tabel 2 Tabulasi nilai prediksi sampel testing set membandingkan jumlah TN (True Negative) dengan dengan model PLS-DA

\begin{tabular}{clcc}
$\begin{array}{c}\text { Model } \\
\text { PLS-DA }\end{array}$ & Sampel & $\begin{array}{c}\text { Nilai } \\
\text { prediksi }\end{array}$ & $\begin{array}{c}\text { Nilai } \\
\text { referensi }\end{array}$ \\
\hline \multirow{3}{*}{ A } & 1 bulan & 0 atau 1 & 1 \\
& 2 bulan & 0 atau 1 & 0 \\
& 3 bulan & 0 atau 1 & 0 \\
B & 1 bulan & 0 atau 1 & 0 \\
& 2 bulan & 0 atau 1 & 1 \\
& 3 bulan & 0 atau 1 & 0 \\
C & 1 bulan & 0 atau 1 & 0 \\
& 2 bulan & 0 atau 1 & 0 \\
& 3 bulan & 0 atau 1 & 1 \\
\hline
\end{tabular}
jumlah FP (False Positive).

\section{Pembuatan Tabulasi Silang dan Validasi Kualitatif (Cuadros-Rodríguez et al.2016)}

Uji kinerja kualitatif metode menggunakan sampel testing set yang telah dipersiapkan. Sebanyak masingmasing 20 sampel $\mathrm{A}, \mathrm{B}$ dan $\mathrm{C}$ diukur nilai reflektansnya, kemudian diolah nilai prediksinya menggunakan model yang diperoleh dari PLS-DA. Jumlah ketepatan klasifikasi dari masing-masing pengukuran akan memengaruhi 4 kemampuan kualitatif metodenya. Terdapat lima kemungkinan klasifikasi yang terjadi, misalkan untuk contoh model $A$, yaitu $A$ terklasifikasi $A$ (TP), A terklasifikasi $B$ atau $C$ disebut NotA (FP), NotA terklasifikasi A (FN), NotA terklasifikasi NotA (TN). Ini dipermudah dengan pembuatan confusion matrix untuk masing-masing model. Parameter validasi terdiri dari 4 yaitu sensitivitas (SENS), spesifitas (SPEC), presisi, dan akurasi.

Sensitivitas. Sensitivitas menunjukkan kepekaan metode memisahkan sampel ke dalam usianya. Nilai terbesar sensitivitas sebesar 1 , yang artinya dapat mengklasifikasikan sampel A, B, atau C secara sempurna. Nilai sensitivitas dihitung dengan membandingkan jumlah TP (True Positive) dengan jumlah FN (False Negative).

$$
\mathrm{SENS}=\frac{\mathrm{TP}}{\mathrm{TP}+\mathrm{FN}}
$$

Spesifisitas. Spesifisitas menunjukkan kepekaan metode memisahkan sampel yang bukan usianya. Nilai terbesar spesifitas sebesar 1 , yang artinya dapat mengklasifikasikan sampel NotA, NotB, atau NotC secara sempurna. Nilai sensitivitas dihitung dengan
Akurasi. Nilai akurasi menunjukkan kedekatan nilai prediksi dengan nilai sebenarnya. Nilai akurasi 1 menunjukkan sampel terprediksi benar $100 \%$ kedalam kelompokya. Nilai akurasi dihitung dengan membandingkan TP dan TN dengan total keseluruhan sampel.

$$
\text { Akurasi }=\frac{\mathrm{TP}+\mathrm{TN}}{\text { Total }}
$$

\section{HASIL DAN PEMBAHASAN}

\section{Karakteristik Sampel Daun Wungu}

Tanaman wungu (Graptophyllum pictum (L.) Griff) ditemukan pertama kali di Irian dan Polynesia, dapat ditemukan dari dataran rendah sampai pegunungan dengan ketinggian 1.250m dpl (Dalimartha 1999). Daun tanaman wungu selain dimanfaatkan untuk mengatasi wasir, juga banyak digunakan untuk penyembuhan luka dan memar pada tubuh oleh masyarakat asia tenggara (Wiart et al. 2006). Tanaman wungu terdiri dari 21 batang. Sehingga terdapat 7 batang untuk tiap bulannya. Jumlah batang yang digunakan lebih dari satu untuk memaksimalkan keragaman sehingga model yang telah dibuat menjadi lebih akurat. Setelah semua batang dipangkas daunnya, dilakukan pengontrolan selama daun mengalami pertumbuhan dengan memberi label dan menyingkirkan hama/ulat. Sebelum analisis dilanjutkan perhitungan kadar air penting dilakukan untuk mengetahui cara penyimpanan sampel. Kadar air yang diperoleh memiliki rerata $10.16 \%$, yang telah memenuhi syarat yang diajukan Depkes (2010) yaitu $\leq 10 \%$. 


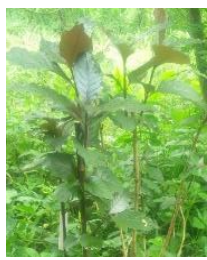

a)

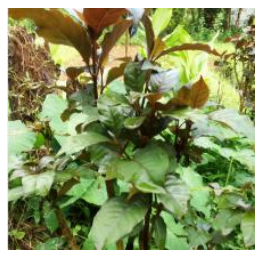

b)

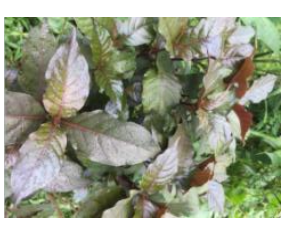

c)

Gambar 2 Daun wungu (a) usia 1 bulan, (b) usia 2 bulan, dan (c) usia 3 bulan

Daun berumur satu bulan yang telah dipangkas umumnya memiliki ukuran daun yang lebih kecil dibandingkan usia 2 bulan dan 3 bulan. Dari segi warna daun, daun yang berumur 3 bulan memancarkan warna ungu khas yang lebih pekat dibandingkan umur 1 bulan yang sepenuhnya hampir berwarna hijau terang (Gambar 2). Sehingga korelasi perubahan warna daun dari usia 1 bulan hingga 3 bulan ini dengan senyawa metabolit yang dikandungnya dilihat dari pola sidikjari kromatografi lapis tipis (Gambar 3).

Kromatografi lapis tipis (KLT) merupakan teknik kromatografi yang digunakan untuk memisahkan campuran komponen berdasarkan distribusi komponen tersebut diantara dua fase, yaitu fase diam dan fase gerak (Stoenoiu 2006). KLT akan menunjukkan perbedaan keterpisahan dari kandungan senyawa pada ketiga sampel daun wungu. Prinsip kerja KLT adalah sampel diaplikasikan pada lapisan tipis lempeng KLT kemudian dilakukan pengembangan di dalam chamber yang berisi fase gerak sehingga sampel akan terpisah

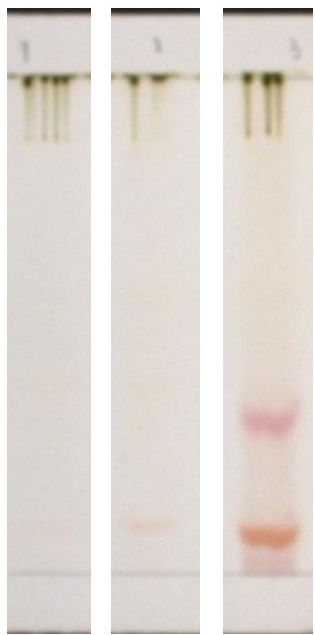

(a)
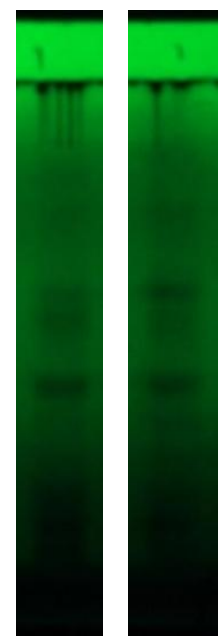

(b) menjadi komponen-komponennya. Fase diam yang umum digunakan adalah silika gel, aluminium oksida, selulosa beserta turunannya, dan poliamida. Komponen yang ingin dipisahkan akan terjerap pada permukaan fase diam atau disebut dengan prinsip adsorbsi.

Analisis sidik jari menggunakan KLT pada penelitian ini bertujuan untuk membandingkan model hasil pengukuran menggunakan spektrofotometer reflektans Quali-Vis dengan metode primer. Pola sidik jari KLT yang dihasilkan dapat menunjukkan pita senyawasenyawa yang dikandung oleh tanaman daun wungu pada usia 1 bulan, 2 bulan, dan 3 bulan. Hasil analisis ini menunjukkan perbedaan intensitas warna pita pada nilai Rf yang sama dengan kata lain adanya perbedaan konsentrasi suatu senyawa antara usia 1, 2, dan 3 bulan. Terdapat 2 pita yang tidak muncul di usia 1 dan 2 bulan, sedangkan muncul di usia 3 bulan yang terletak diantara pita 9 dan 10 (Gambar 3c). Ini menandakan kemungkinan senyawa-senyawa baru akan muncul pada usia yang lebih tua.

Gambar 3 menunjukkan hasil totolan ekstrak daun wungu dalam metanol menghasilkan senyawa berwarna ungu yang terdeteksi pada sinar tampak, sehingga jika dikaitkan dengan uv-vis maka senyawa berwarna ungu akan menyerap warna komplementernya yaitu kuning pada panjang gelombang 570-590 $\mathrm{nm}$. Ini terlihat pada spektrum reflektans terukur Quali-vis pada gambar 8
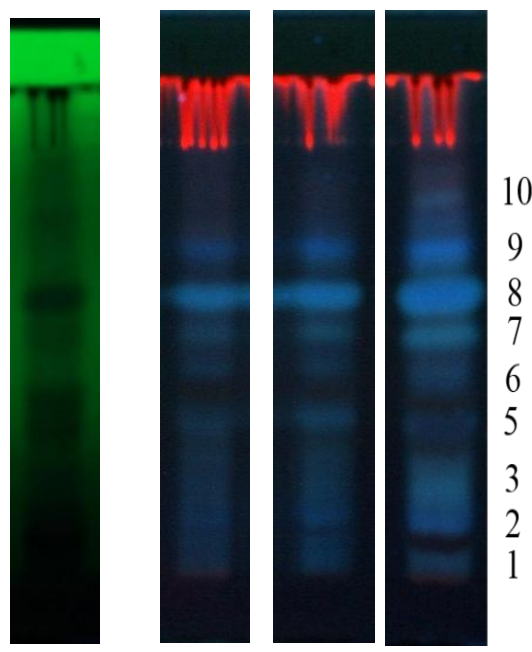

(c)

Gambar 3 Pita sidik jari kromatografi lapis tipis daun wungu pada (a) UV tampak, (b) UV 254 nm dan (c) UV $366 \mathrm{~nm}$ 
menghasilkan spektrum yang khas dengan penurunan nilai reflektans. Terdapat 10 pita yang muncul pada pelat dengan campuran eluen etil asetat ; asam format ; asam asetat glasial ; air $(10 ; 1.1 ; 1.1 ; 2)$.
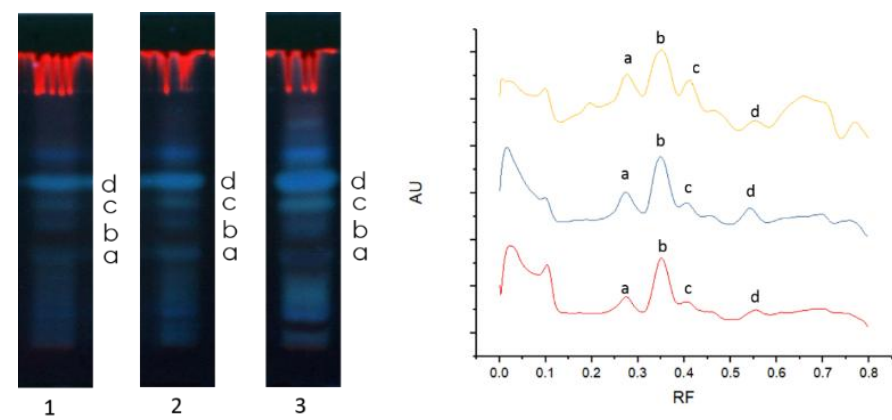

Gambar 4 Pelat KLT $366 \mathrm{~nm}$ dan interpretasi dengan image ( - ) usia 1 bulan, ( - ) usia 2 bulan, (-) usia 3 bulan

Pita menunjukkan perbedaan yang jelas terdapat pada pita d untuk masing-masing usia 1, 2 dan 3 bulan. Pita $d$ pada pita klt untuk usia 3 bulan menunjukkan intensitas pita yang lebih besar, yang menunjukkan bahwa senyawa yang dikandungnya juga lebih besar. Gambar 4 menunjukkan interpretasi pita menjadi puncak. Masing-masing pita yang memiliki ketebalan yang berbeda-beda dapat diketahui nilainya melalui luas area puncak yang muncul tersebut. Semakin tebal pita, maka luas puncak yang dihasilkan pun semakin besar. Berikut tabel dan nilai Rf yang menunjukkan puncak yang telah ditandai tersebut.

Masing-masing puncak memiliki luas yang berbeda. Pembacaan Tabel 3 dimulai dari membandingkan puncak a untuk masing-masing bulan. Begitu pun

Tabel 3 Luas puncak dan nilai RF pita KLT 366 nm

\begin{tabular}{|c|c|c|c|c|}
\hline Sampel & Peak & Area & Intensitas (\%) & RF value \\
\hline \multirow[t]{4}{*}{ Usia 1 bulan } & $a$ & 2716.26 & 30.76 & 0.29 \\
\hline & $b$ & 5579.43 & 63.18 & 0.36 \\
\hline & c & 535.65 & 6.07 & 0.41 \\
\hline & $d$ & 739.41 & 19.55 & 0.56 \\
\hline \multirow[t]{4}{*}{ Usia 2 bulan } & $a$ & 3949.50 & 30.42 & 0.28 \\
\hline & $b$ & 8361.47 & 64.41 & 0.33 \\
\hline & c & 671.53 & 5.17 & 0.41 \\
\hline & d & 1477.36 & 39.06 & 0.55 \\
\hline \multirow[t]{4}{*}{ Usia 3 bulan } & $a$ & 2196.86 & 18.43 & 0.28 \\
\hline & $b$ & 6078.74 & 51.00 & 0.35 \\
\hline & c & 3643.88 & 30.57 & 0.41 \\
\hline & $\mathrm{d}$ & 1565.62 & 41.39 & 0.56 \\
\hline
\end{tabular}

seterusnya untuk puncak b, c, dan d. Beberapa puncak menunjukkan data yang menarik dimana usia 1 bulan memiliki pita yang lebih tebal dibandingan dengan pita pada usia 2 bulan pada beberapa puncak. Ini menunjukkan bahwa beberapa senyawa memiliki jumlah konsentrasi optimal pada usia yang lebih muda. Pada puncak $\mathrm{c}$ dan puncak $\mathrm{d}$ menunjukkan luas puncak yang besar berturut-turut untuk usia 1 bulan, 2 bulan, dan 3 bulan. Sehingga klasifikasi yang baik oleh spektrofotometer reflektans Quali-Vis dan pemodelan kemometrika mampu terbentuk karena pola sidikjari KLT menghasilkan perbedaan pada luas puncak untuk sampel usia 1 bulan, 2 bulan dan 3 bulan.

Perbedaan warna daun wungu pada masing-masing usia berhubungan dengan perbedaan pola sidikjari yang dihasilkan. Pola sidikjari yang berbeda untuk masing-masing usia panen menjadi dasar klasifikasi sampel dengan menggunakan spektrofotometer.

Metode spektrofotometer uv-vis sangat berkaitan erat dengan warna yang dapat dilihat pada rentang sinar tampak yaitu 350-750, yang mana juga merupakan rentang panjang gelombang yang dapat dilihat oleh mata manusia. Spektrofotometer sinar tampak reflektans Quali-Vis ini akan menghasilkan reflektans yang rendah seiring dengan banyaknya sinar yang dapat diserap oleh warna tertentu. Semakin pekat warna, maka sinar yang akan diserap akan semakin banyak sehingga nilai reflektans tinggi.

\section{Kalibrasi Quali-Vis dan Karakteristik spektrum reflektans}

Rentang panjang gelombang yang tepat akan mempengaruhi pengukuran sampel, oleh sebab itu 
perlu dilakukan kalibrasi terhadap spektrofotometer reflektans sinar tampak Quali-Vis. Kalibrasi penting dilakukan agar tercapai kesesuaian hasil pengukuran, serta dapat ditentukannya nilai penyimpangan (Morris 2001). Kalibrasi secara khusus dilakukan pada spektrofotometer Quali-Vis dengan mengganti lampu LED menjadi lampu neon sebagai sumber cahaya dan pelet $\mathrm{BaSO}_{4}$ sebagai referensi berwarna putih. Lampu neon sebagai lampu CFL digunakan sebagai sumber cahaya untuk kalibrasi sebab lampu neon mengandung gas inert dan uap merkuri yang memiliki spektrum khas pada panjang gelombang $436 \mathrm{~nm}$ dan $546 \mathrm{~nm}$ (Gambar 5).

Menurut spectralworkbench, kalibrasi yang baik yaitu jika mencapai fit kurang dari 10, yang mana kalibrasi yang didapatkan memiliki fit 8 . Hasil kalibrasi yang paling baik sejauh ini adalah milik Jeffrey Warren cofounder publiclab yang mendapatkan fit 7. Panjang gelombang yang didapatkan dari hasil kalibrasi ini akan menjadi rentang panjang gelombang untuk pengukuran reflektans sampel, yaitu pada rentang dari 293.6-860.0 $\mathrm{nm}$.

Spektrofotometer Quali-Vis yang telah dikalibrasi, selanjutnya diamati spektrum blanko dan sampel. Blanko yang digunakan adalah $\mathrm{BaSO} 4$ yang berwarna putih dan transparan pada sinar tampak. Menurut BPOM (2016), $\mathrm{BaSO}_{4}$ tidak memiliki efek klinis yang serius meskipun adanya kontak langsung pada kulit kecuali jika tertelan. Selain itu harga yang ekonomis, membuat BaSO4 selalu digunakan pada penelitian yang berkaitan dengan Quali-Vis. Blanko diharapkan mampu memantulkan seluruh sinar datang ke detektor sehingga diperoleh spektrum sinar pantul dengan nilai maksimum. Blanko BaSO4 yang mampu memantulkan seluruh sinar datang akan menghasilkan spektrum dengan intensitas pantulan yang tinggi pada seluruh panjang gelombang serta meminimumkan tranmisi sinar. Sebaliknya, sampel yang memiliki matriks dan pigmen yang berpengaruh pada pemantulan sinar akan menghasilkan spektrum dengan intensitas pantulan lebih rendah (Gambar 6). Sampel yang memiliki warna tidak putih atau berwarna menyebabkan adanya serapan pada panjang gelombang tertentu. Adanya serapan menyebabkan berkurangnya intensitas pantulan yang terukur.

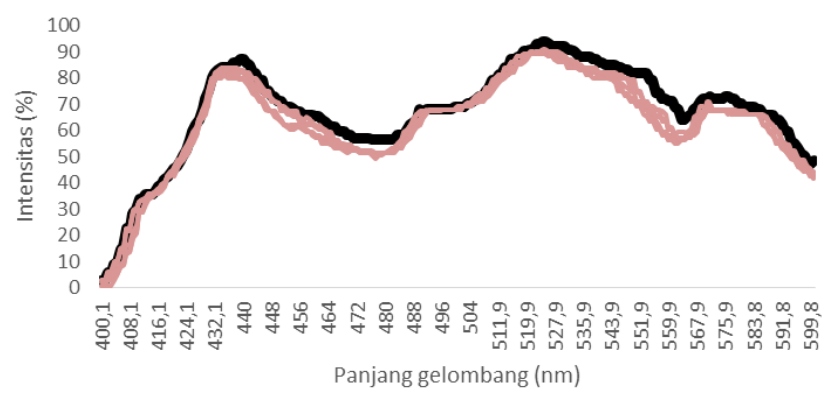

Gambar 6 Spektrum intensitas (a) blanko dan (b)
sampel

Wadah sampel terdiri atas dua kaca preparat sejajar yang diantara kedua kaca tersebut diletakkan sampel. Selain sebagai wadah sampel, kaca preparat juga berfungsi sebagai medium tranmisi dan pantulan sinar. Bahan utama berupa borosilikat pada kaca preparat mampu menyerap sinar pada panjang gelombang UV $(<$ $350 \mathrm{~nm})$. Sehingga pengamatan spektrum dalam panjang gelombang sinar tampak pada penelitian ini dapat menghasilkan sinyal yang tepat. Hasil yang diperoleh berupa sinar yang terpantulkan ketika mengenai sampel akan diubah menjadi spektrum warna oleh kisi. Kisi berupa optik DVD yang ditempelkan pada bagian depan detektor yang merupakan kisi difraksi yang memiliki 1350 garis/mm

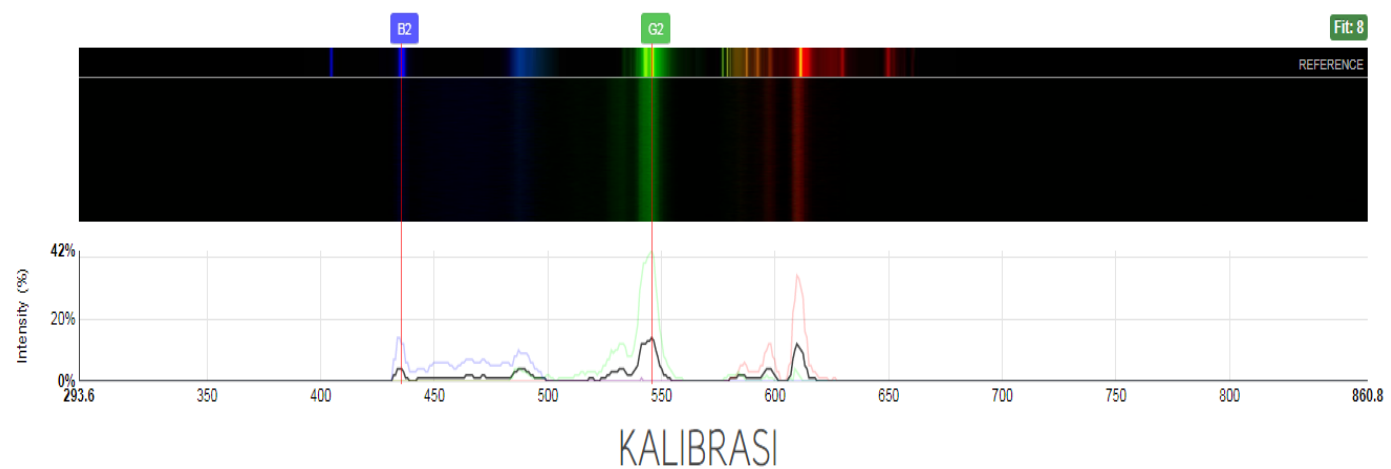

Gambar 5 Hasil kalibrasi spektrofotometer Quali-Vis menggunakan lampu neon 
(Wakabayashi \& Hamada 2006).

Komponen senyawa kimia akan menyerap, mentransmisikan ataupun memantulkan cahaya pada rentang panjang gelombang tertentu atau biasa disebut radiasi elektromagnetik. Perbedaan yang nyata diantara komponen tertentu adalah dari warna.

Sampel yang berwarna memiliki intensitas pantulan yang lebih rendah dibandingkan intensitas pantulan blanko. Hal ini menunjukkan adanya serapan pada sampel. Tablet serbuk daun wungu yang berwarna hijau akan menyerap warna komplementernya yaitu warna ungu-merah. Hijau merupakan warna yang unik karena penyerapan warna komplementer berupa merah yang mendekati panjang gelombang 800 juga sebaik warna komplementer berupa ungu yang mendekati 400 (Gambar 7). Spektrofotometer Quali-Vis merupakan spektrofotometer reflektans uv-vis yang masih dalam pengembangan dan mampu mendeteksi sinyal pada rentang panjang gelombang 400-600. Sehingga untuk tahap pengembangan model selanjutnya dilakukan pengamatan menyeluruh reflektans dari panjang gelombang 400-600. Lalu dipilih rentang pada reflektans yang mulai memberikan perbedaan yang nyata pada sampel yakni pada rentang 450-600.

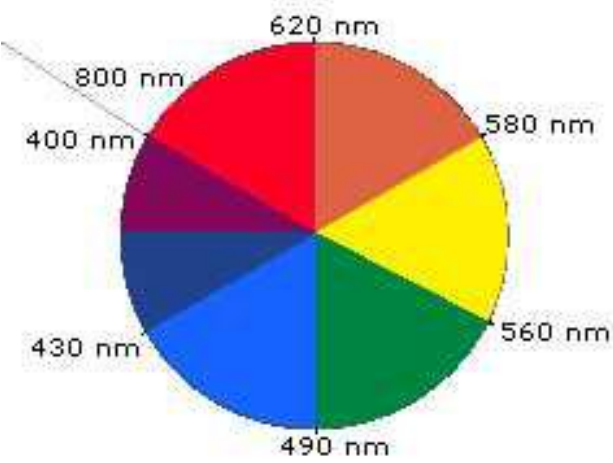

Gambar 7 Warna komplementer (Sanda et al. 2012)

Daun wungu usia 1 bulan memiliki warna yang lebih muda atau terang dibandingkan daun usia 2 bulan dan 3 bulan. Daun wungu usia 1 bulan memiliki intensitas serapan yang lebih rendah karena kandungan senyawa metabolit yang lebih sedikit dibandingkan daun dengan usia yang lebih tua. Sehingga konversi nilai intensitas serapan menjadi reflektans menjadikan nilai reflektans usia 1 bulan lebih tinggi. Daun wungu usia 3 bulan memiliki intensitas serapan yang lebih tinggi sehingga nilai reflektans yang dihasilkan paling rendah dibandingkan usia daun yang lebih muda lainnya (Gambar 8). Ini sesuai dengan pendapat Hafshah (2017) yang meneliti temulawak yang segar dan sudah lama disimpan. Temulawak segar yang memiliki kandungan senyawa metabolit yang lebih tinggi memiliki nilai reflektans yang lebih rendah.

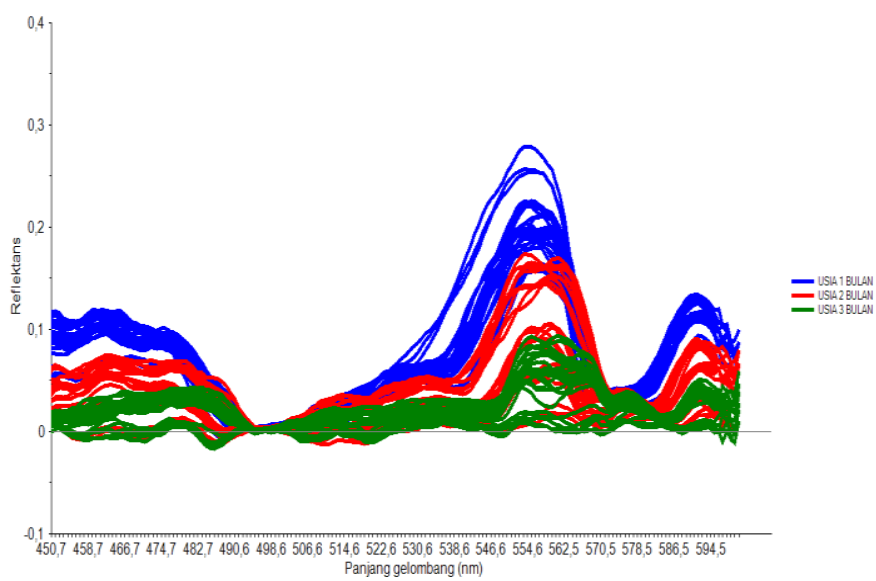

Gambar 8 Spektrum reflektans daun wungu usia 1 bulan $(-)$, usia 2 bulan $(-)$, dan usia 3 bulan $(-)$

\section{Model klasifikasi Sampel A, B, dan C}

Sampel daun wungu dibagi menjadi $A, B$, dan $C$ yang merupakan representasi dari masing-masing daun wungu usia 1 bulan, 2 bulan, dan 3 bulan. Klasifikasi sampel diawali dengan pembuatan model. Model dibuat menggunakan data training set. Training set terdiri atas 60 data reflektans dari masing-masing kelas yang diukur pada waktu kerja yang sama. Data reflektans tersebut diolah menggunakan perangkat lunak The Unscrambler $\mathrm{X}$ versi 10.1. Proses pengolahan dimulai dari preprocessing. Tujuan utama dari preprocessing adalah untuk mengurangi variasi $\mathrm{di}$ dalam data yang tidak berpengaruh pada informasi analitik (Zeaiter dan Rutledge 2009). Preprocessing atau perlakuan pendahuluan yang tepat akan memberikan pola distibusi yang baik antar masingmasing kelompok sampel. Sehingga perlu dilakukan eksplorasi yang menyeluruh terhadap data terlebih dahulu. Preprocessing yang digunakan adalah smoothing Savitsky-Golay dengan 15 moving window. Algoritma savitsky-golay menyesuaikan kurva segmen dengan bentuk polinomial serta mengganti nilai awal dnengan ragam yang lebih sederhana. Metode ini sangat baik untuk menghilangkan noise pada spektra sekaligus menyimpan informasi analitik (CAMO 2006). 
Principle component analysis (PCA) adalah teknik yang digunakan untuk meringkas struktur dari data yang rumit dan kompleks sekaligus menunjukkan keberagaman varians serta cara sampel dapat dibedakan dari sampel lain. Fungsi utama penggunaan PCA untuk membedakan tiap sampel yang ditunjukkan dengan terbentuknya kelompok pada PC tertentu. Berikut merupakan hasil akuisisi data menggunakan PCA.

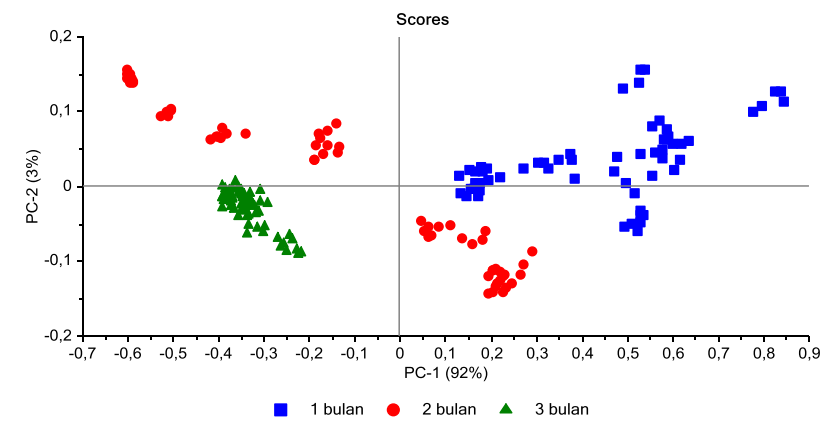

Gambar 9 Plot skor PCA untuk usia 1 bulan ( $\square$ ), usia 2 bulan (C), usia 3 bulan ( $)$

PCA mampu merepresentasikan hasil analisis dengan baik melalui pengelompokan berdasarkan kemiripan sifat. Sampel A, B, dan C akan terkelompok sesuai bulannya karena kemiripan sifat yang dimiliki. Plot skor mendeskripsikan struktur data dalam bentuk pola sampel, dan secara umum menunjukkan perbedaan dan persamaan antara satu data dengan yang lainnya. Berdasarkan Gambar 9, sampel berhasil dipisahkan menjadi 3 kelas, yaitu A, B, dan C dengan total PC 95\%. Nilai PC yang tinggi menunjukkan bahwa model berhasil menjelaskan $95 \%$ bagian dari data spektrum beserta ragam dan komponennya. Pada usia 2 bulan terlihat adanya subkelas yang terjadi karena adanya kecendrungan warna sampel usia 2 bulan mendekati usia 1 bulan dan juga 3 bulan yang terlihat pada spektrum reflektans terukur (Gambar 8).

Analisis multivariat lain yang digunakan adalah PLSDA. Partial least square-discriminant analysis (PLS-DA) merupakan analisis yang berguna untuk mengoptimalkan pemisahan antar kelompok sampel yang berbeda. Sedikit berbeda dengan PCA, PLS-DA dilakukan untuk mempertajam pemisahan antar kelompok sampel dan dapat mengetahui variabel mana yang memisahkan kelas sampel (Gromski et al. 2015). PLS-DA mampu menentukan model prediktif yang akan diuji kemampuan kualitatifnya dalam mengklasifikasi sampel. Matriks-x yang diperlukan ada pembuatan model ialah hasil pengukuran spektra reflektans, sedangkan matriks-y merupakan variabel referens acak yang terdiri dari angka 1 dan 0 yang disebut dengan dummy varible. Terdapat 3 matriks-y yang digunakan sebagai representasi model validasi yang dibuat yaitu ModA, ModB, dan ModC. ModA dengan kombinasi 1, 0, dan 0 untuk masing-masing sampel $A, B$, dan $C$ berturut-berturut. Selanjutnya diikuti ModB dengan kombinasi 0,1 , dan 0 . Lalu ModC dengan kombinasi 0 , 0 , dan 1 .

Tabel 4 Nilai R-square dan Root Mean Square Error model PLS-DA

\begin{tabular}{lllll}
\hline \multirow{2}{*}{ Model } & \multicolumn{2}{l}{ Kalibrasi } & \multicolumn{2}{l}{ Validasi } \\
\cline { 2 - 5 } & $\mathrm{R}^{2}$ & RMSE & $\mathrm{R}^{2}$ & RMSE \\
\hline ModA & 0.8782 & 0.1646 & 0.8366 & 0.1922 \\
ModB & 0.7289 & 0.2454 & 0.6370 & 0.2866 \\
ModC & 0.8870 & 0.1584 & 0.8645 & 0.1752 \\
\hline
\end{tabular}

Dari tiga model yang telah dibuat yaitu model A, B dan $C$ didapatkan hasil R-square dan RMSE yang berbeda-beda (Lampiran 4). Jika R-square yang didapatkan mendekati 1 dan RMSE mendekati 0, maka model yang telah dibentuk bisa dikatakan baik. Model A dan $C$ memiliki nilai $R$ yang lebih besar dari model $B$ dan memiliki persen error yang lebih kecil, sehingga dapat dikatakan model $\mathrm{A}$ dan $\mathrm{C}$ merupakan model yang lebih baik (Tabel 4). Berdasarkan nilai tersebut model A dan $C$ yang dibentuk dapat mengklasifikasikan masingmasing usia 1 bulan dan 3 bulan dengan baik. Hal ini sebenarnya sudah digambarkan cukup jelas dari plot skor PCA (Gambar 9), dimana usia 1 dan 3 bulan terkelompok cukup baik pada 1 kuadran, sedangkan usia 2 bulan pengelompokkannya terpisah dalam 2 kuadran. Hal ini disebabkan karena usia 2 bulan memiliki warna yang mirip dengan usia 1 dan 3 bulan, sehingga nilai reflektans yang dihasilkan juga berkisar antara nilai reflektans usia 1 bulan dan 3 bulan. Pernyataan ini juga diperkuat dengan plot line yang dihasilkan (Gambar 8), bahwa usia 2 bulan mengalami tumpang tindih spektrum dengan spektrum usia 1 bulan maupun 3 bulan.

Model PLS-DA yang didapatkan sudah mampu memprediksi data testing set sesuai kelompoknya dengan cukup baik (Lampiran 5, 6, 7). Hal ini ditunjukkan dengan nilai yang mendekati 1 untuk semua parameter dengan menggunakan metode interpretasi tabulasi silang (confusion matrix) (Lampiran 
8). Interpretasi data hasil prediksi menggunakan tabulasi silang memiliki kelebihan mampu menvisualisasikan performa suatu model dengan algoritma yang lebih sederhana. Parameter yang dapat ditentukan dari tabulasi silang ini antara lain yaitu sensitivitas, spesifitas, presisi, dan akurasi.

Tabel 5 Interpretasi hasil prediksi model A, model B, dan model $\mathrm{C}$ dengan tabulasi silang

\begin{tabular}{|l|l|c|c|}
\cline { 3 - 4 } \multicolumn{2}{c|}{} & \multicolumn{2}{c|}{ Actual class } \\
\cline { 3 - 4 } \multicolumn{1}{c|}{} & $\mathrm{A}$ & $\mathrm{A}$ & Not A \\
\cline { 2 - 4 } & Not A & 20 & 0 \\
\cline { 2 - 4 } & & 0 & 40 \\
\cline { 2 - 4 } $\begin{array}{l}\text { Predicted } \\
\text { class }\end{array}$ & $\mathrm{B}$ & $\mathrm{B}$ & Not B \\
\cline { 2 - 4 } & Not B & 18 & 1 \\
\cline { 2 - 4 } & & 2 & 39 \\
\cline { 2 - 4 } & $\mathrm{C}$ & $\mathrm{C}$ & Not C \\
\cline { 2 - 4 } & Not C & 19 & 0 \\
\hline
\end{tabular}

Model A menghasilkan nilai akurasi maupun semua parameter yaitu 1, yang berarti semua sampel testing set untuk usia 1 bulan dapat terprediksi $100 \%$ pada kelompoknya. Sedangkan model B menunjukkan adanya 2 sampel yang tak masuk kedalam kelas usia 2 bulan, dan 1 sampel yang bukan merupakan usia 2 bulan terdeteksi ke dalam kelas usia 2 bulan. Sehingga model B menghasilkan nilai akurasi sebesar 0.95 . Model $C$ menunjukkan nilai parameter yang lebih baik dibandingkan model $\mathrm{B}$, yang mana hanya terdapat 1 sampel usia 3 bulan terdeteksi ke dalam kelas yang bukan usia 3 bulan. Sehingga model $C$ menunjukkan nilai akurasi 0.98 (Tabel 5). Berdasarkan nilai akurasi tersebut klasifikasi daun wungu dengan perbedaan usia panen menggunakan spektrofotometer reflektans Quali-Vis dan analisis multivariat kemometrika PCA dan PLS-DA dapat mengelompokkan sampel sesuai kelasnya dengan baik.

\section{SIMPULAN}

Pengukuran sampel dengan spektrofotometer reflektans Quali-vis dan pemodelan menggunakan kemometrika analisis multivariat menghasilkan klasifikasi yang baik untuk sampel usia 1 bulan, 2 bulan, dan 3 bulan. Terlihat dari jumlah PC yang besar yaitu
95\% pada pemodelan menggunakan PCA. Model PLSDA yang terbentuk memiliki rerata R-square kalibrasi dan validasi berturut-turut sebesar $83.14 \%$ dan $77.94 \%$. Hasil prediksi model PLS-DA menunjukkan nilai akurasi 1 dengan sampel terklasifikasi $100 \%$ sesuai kelompoknya untuk model A. Sehingga model A merupakan model yang paling baik klasifikasinya, dan model B merupakan model yang cukup baik dalam mengklasifikasikan daun wungu usia 2 bulan dengan nilai akurasi prediksi terkecil dari ketiga model yaitu sebesar 0.95. Model C menghasilkan nilai akurasi prediksi sebesar 0.98. Sehingga spektrofotometer Quali-Vis mampu mengklasifikasikan sampel daun wungu berdasarkan perbedaan usia panen yaitu usia 1 bulan, 2 bulan, dan 3 bulan.

\section{DAFTAR PUSTAKA}

[AOAC] Association of Official Analytical Chemist. 2007. Official method of Analysis of Analysis. Ed ke-14. Aelington: AOAC.

CAMO. 2006. The Unscrambler User Manual: The Unscrambler Methods. New

York (US): CAMO Software AS.

[Depkes RI] Departemen Kesehatan Republik Indonesia. 2010. Farmakope Herbal Indonesia Edisi I. Jakarta (ID): Depkes RI.

Antari PD. 2015. Spektrofotometer Uv-Vis reflektans dan kemometrika sebagai teknik klasifikasi spesimen jaringan kanker serviks dan normal. [skripsi]. Bogor (ID): Institut Pertanian Bogor.

Anuradha VE, Jaleel CA, Salem MA, Gomathinayagam $M$, Panneerselvam R. 2010. Plant growth regulators induced changes in antioksidant potential and andrographolide content in Andrographis paniculata Wall ex Nees. Pestic Biochem Physiol. 98:312-316.

Aminah, Muflihunna A, Abidin Z. 2016. Uji aktivitas antioksidan fraksi etil asetat daun wungu (Graptophyllum pictum (Linn) Griff) dengan metode FRAP (Ferric Reducing Antioxidant Power). Assyifaa. 8(1):39-44

Astuti Al. 2015. Kuantifikasi kurkuminoid dalam temulawak menggunakan spektrofotometer reflektans berbasis CCD. [skripsi]. Bogor (ID): Institut Pertanian Bogor.

Blum-Silva CH, Chaves VC, Schenkel EP, Coelho GC, Reginatto FH. 2015. The influence of leaf age on methylxanthines, total phenolic content, and free

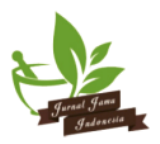


radical scavenging capacity of Ilex paraguariensis aqueous extracts. Rev. Bras. Farmacogn. 25:1-6

Cuadros-Rodriguez L, Perez-Castano E, Ruiz-SamblasC. 2016. Quality performance metrics in multivariate classification methods for qualitative analysis. TRAC-Trend Anal Chem. 80:612-624

Dalimartha. 1999. Ramuan Tradisional Untuk Pengobatan Hepatitis. Jakarta: Penebar Swadaya.

Gromski P, Muhammadali H, Ellis D, Xu Y, Correa E. 2015. A tutorial review: metabolomics and partial least squares-discriminant analysis-a marriage of convenience or a shotgun wedding. Anal Chim Acta. 879:10-23

Hafsah N. 2017. Validasi kualitatif model klasifikasi kualitas temu lawak menggunakan spektrofotometer reflektans Quali-Vis dan Kemometrika[skripsi]. Bogor (ID): Institut Pertanian Bogor.

Jiangseubchatveera N, Liawruangrath $\mathrm{S}$, Teerawutgulrag A, Santiarworn D, Pyne SG, Liawruangrath B. 2017. Phytochemical screening, phenolic and flavonoid contents, antioxidant and cytotoxic activities of Graptophyllum pictum (L.) Griff. Chiang Mai J SCI. 44:193-202.

Mardiana E. 2017. Uji kinerja analitik spektrofotometer sinar tampak berbasis reflektans menggunakan pewarna sudan. [skripsi]. Bogor (ID): Institut Pertanian Bogor.
Morris AS. 2001. Measurement and Instrumentation Principles. London (GB):

Butterworth-Heinemann.

Rahma N. 2016. Spektrofotometer reflektans sinar tampak dan kemometrika sebagai kendali mutu daun jati belanda (Guazuma ulmifokia). [skripsi]. Bogor (ID): Institut Pertanian Bogor.

Sanda Fm, Victor Me, Monica Ta, Alina C. 2012. Spectrophotometric Measurements Techniques for Fermentation Process. Romania: University of Oradea

Singh SK, Jha SK, Chaudhary, Yadava RDS, Rai SB. 2010. Quality control of herbal medicines by using spectroscopic techniques and multivariate statistical analysis. Phram Biol. 48:134-141

Stoenoiu CM, Bolbocoa AD, Jansthi L. 2006. Mobile phase optimization for steroid separation. Med Informatics. 16:141-148

Wakabayashi F, Hamada K. 2006. A DVD spectroscope: a simple, high-resolution classroom spectrosope. J Chem Educ. 83:56-58

Wiart C. 2006. Medicinal Plants of the Asia-Pacific: Drugs for the Future. Singapura: World Scientific Publishingh Co, Ltd.

Zeaiter M, Rutledge DN. 2009. Comprehensive Chemometrics. Amsterdam (NL): Elsevier.

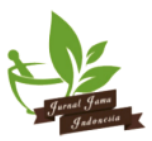

